\title{
Herança da informação digital e direito ao esquecimento em redes sociais on-line: uma revisão sistemática de literatura
}

\author{
Simone de Assis Alves da Silva \\ Doutoranda; Universidade Fundação Mineira de Cultura, Belo Horizonte, MG, Brasil; \\ simonedaas@gmail.com \\ Luiz Cláudio Gomes Maia \\ Doutor; Universidade Fundação Mineira de Cultura, Belo Horizonte, MG, Brasil; \\ luiz.maia@fumec.br \\ Rafael Lelis Rafacho \\ Mestrando; Universidade Fundação Mineira de Cultura, Belo Horizonte, MG, Brasil; \\ rafael.rafacho@yahoo.com.br \\ Paulo Sérgio Monte Alto \\ Mestrando; Universidade Fundação Mineira de Cultura, Belo Horizonte, MG, Brasil; \\ paulomontealto@bol.com.br \\ André Luiz Ogando Pereira \\ Mestrando; Universidade Fundação Mineira de Cultura, Belo Horizonte, MG, Brasil; \\ andreogando@yahoo.com.br
}

\begin{abstract}
Resumo: Com a evolução e a expansão da Internet, pode-se observar a criação e a difusão das redes sociais on-line, que são serviços digitais para conectar diferentes usuários por meio de perfis públicos ou semipúblicos. Nesse cenário, iniciam-se os estudos acerca das redes sociais e de seus desdobramentos na sociedade, como a herança digital, entendida como o acervo digital (fotos, mensagens, vídeos etc.) deixados em vida pelo usuário. Após a inatividade do perfil de um usuário devido ao seu falecimento, é importante dar o devido tratamento a essa herança deixada por ele. Assim, aparece como dispositivo legal o Direito ao Esquecimento, que em seu cerne conceitual propõe ora o direito ao acesso a informação e liberdade de expressão ora o direito à intimidade e à privacidade, capaz de resguardar ao titular de determinado dado a faculdade de vê-lo apagado, suprimido ou bloqueado. $O$ presente artigo apresenta o resultado de uma Revisão Sistemática de Literatura, com o propósito de verificar o atual cenário de pesquisa sobre o direito ao esquecimento e herança digital no contexto das redes sociais on-line e identificar sob qual enfoque os estudos estão sendo realizados. Foi possível auferir que, no atual cenário de uma sociedade permeada pelos recursos oferecidos pelas Tecnologias da Informação e Comunicação, a maior parte das pesquisas concentra-se nos princípios da intimidade e privacidade sob a prerrogativa do indivíduo frente a essa nova sociedade, o qual exige respostas rápidas e legítimas para a preservação de sua imagem e personalidade nos espaços por onde ele passar.
\end{abstract}

Palavras-chave: Direito ao esquecimento. Herança digital. Redes sociais online. Legado digital. Informação digital. 


\section{Introdução}

A expansão do acesso ao mundo virtual proporcionada pela rede mundial de computadores, Internet, estimulou expressiva popularização dos meios de comunicação, possibilitando a democratização do acesso à informação, bem como o surgimento e o crescimento de um dos fenômenos no mundo digital: as redes sociais on-line (RSO).

A empresa norte-americana eMarketer realizou uma pesquisa em 2016 para mensurar o número de usuários de redes sociais on-line em três países da América Latina, conforme mostra Tabela 1. Entre os países pesquisados, o Brasil lidera desde 2014 a lista composta também por México e Argentina. Em 2017, mais de 97 milhões de usuários apareceram no universo das RSO, seguido por México, com 61,6 milhões de usuários, e Argentina, com 22,5 milhões. Além disso, a empresa fez também uma projeção para os anos de 2018, 2019 e 2020 mostrando um forte crescimento e uma contínua liderança brasileira em número de usuários. Pela pesquisa, em 2020, seremos mais de 105 milhões de usuários. A segunda parte da tabela (social network user growth - \% change) mostra, em percentual, o crescimento do número de usuários ano a ano por país. Embora o Brasil tenha ficado uma posição anterior ao México, o percentual de crescimento ainda se faz expressivo e demonstra o alto nível de acesso e contato com as RSO.

Tabela 1 - Número de usuário das redes sociais on-line

\begin{tabular}{|c|c|c|c|c|c|c|c|}
\hline \multicolumn{8}{|c|}{$\begin{array}{l}\text { Social Network Users in La } \\
2014-2020\end{array}$} \\
\hline+2 & 2014 & 2015 & 2016 & 2017 & 2018 & 2019 & 2020 \\
\hline \multicolumn{8}{|c|}{ Social network users (millions) } \\
\hline Brazil & 78.1 & 86.5 & 93.2 & 97.8 & 100.6 & 103.1 & 105.2 \\
\hline Mexico & 43.7 & 49.5 & 56.0 & 61.6 & 65.9 & 69.8 & 72.1 \\
\hline Argentina & 19.2 & 20.8 & 21.7 & 22.5 & 23.3 & 23.9 & 24.3 \\
\hline Other & 69.0 & 81.0 & 89.3 & 95.9 & 102.0 & 107.7 & 111.9 \\
\hline Latin America & 210.0 & 237.8 & 260.1 & 277.8 & 291.8 & 304.4 & 313.6 \\
\hline \multicolumn{8}{|c|}{ Social network user growth (\% change) } \\
\hline Mexico & $16.7 \%$ & $13.2 \%$ & $13.1 \%$ & $10.0 \%$ & $7.0 \%$ & $6.0 \%$ & $3.3 \%$ \\
\hline Brazil & $12.5 \%$ & $10.7 \%$ & $7.8 \%$ & $5.0 \%$ & $2.8 \%$ & $2.4 \%$ & $2.1 \%$ \\
\hline Argentina & $9.9 \%$ & $8.5 \%$ & $4.2 \%$ & $3.8 \%$ & $3.4 \%$ & $2.6 \%$ & $2.0 \%$ \\
\hline Other & $16.2 \%$ & $17.5 \%$ & $10.3 \%$ & $7.3 \%$ & $6.4 \%$ & $5.6 \%$ & $3.9 \%$ \\
\hline Latin America & $14.3 \%$ & $13.2 \%$ & $9.4 \%$ & $6.8 \%$ & $5.0 \%$ & $4.3 \%$ & $3.0 \%$ \\
\hline
\end{tabular}

Fonte:eMarketer (2016). 
Esses números demonstram que em razão da sua grande popularidade, as redes sociais on-line vêm sendo objeto de estudo em diversas áreas do conhecimento e, assim, a descoberta de seus efeitos na sociedade como um todo tem se apresentado como um desafio.

Ao estudar o universo das RSO, é possível mapear as redes e estabelecer os padrões de comportamentos de usuários, descobrir relações de disseminação e fluxo de informações, compreender determinadas características psicossociais, avaliar seus impactos culturais, sociais e verificar seu uso como fonte de armazenamento e compartilhamento de informações capaz de balizar um legado virtual.

No entanto, Pereira et al. (2010) lembram que apesar da grande popularidade e da considerável quantidade de conteúdo disponível, o estudo das redes sociais on-line ainda é incipiente, uma vez que elas estão experimentando novas tendências e enfrentando novos problemas e desafios resultantes da assimilação, pelos usuários, dos contínuos avanços tecnológicos e do grande volume informacional presentes nesses ambientes.

Partindo desse pressuposto, um dos desafios que se apresenta, atualmente, no universo das RSO diz respeito ao acervo digital, como fotos, vídeos, livros, músicas, mensagens, etc., que são armazenados virtualmente com alcance de espaço e propagação extremamente elevados e que formam a herança digital do usuário que, em atividade, a acumulou ao longo de sua experiência.

Herança, na doutrina do Direito, pode ser definida como a “[...] transmissão dos direitos e obrigações de uma pessoa morta a outra sobreviva, em virtude da lei ou da vontade do transmissor." (BEVILÁQUA, $1978^{1}$ apud COSTA FILHO, 2016). Esse é um dos conceitos relacionados ao termo herança, pois, segundo o autor, existem diversas outras maneiras de defini-lo; entretanto, os conceitos oferecidos não apresentam nenhum empecilho à inclusão do "acervo digital" ao tratar-se de herança, pois o próprio ordenamento jurídico não prevê esse tipo de restrição e expressa ideia abrangente de patrimônio. Torna-se, assim, indispensável abordar um direito personalíssimo ${ }^{2}$ : o direito ao esquecimento, que se apresenta em defesa do indivíduo frente a uma das 
características inerentes às redes sociais, a invasão de privacidade, que por sua vez pode ocasionar o uso indevido do acervo digital do usuário.

Nesse contexto, surgem indagações: quem terá direito aos pertences digitais dos usuários de redes sociais on-line? Um perfil que não está em atividade pode ser manuseado por outras pessoas? E ainda: sob quais perspectivas essa discussão está sendo tratada no âmbito acadêmico?

Partindo dessas questões norteadoras, este artigo apresenta o resultado de uma Revisão Sistemática de Literatura (RSL), cujo objetivo é verificar o panorama de estudos do Direito ao Esquecimento e herança digital deixados pelos usuários de redes sociais on-line.

A estrutura do artigo está organizada da seguinte forma: a segunda seção apresenta os conceitos relacionados a herança digital e Direito ao Esquecimento. $\mathrm{Na}$ terceira seção são apresentados conteúdos relacionados às redes sociais online. A Revisão Sistemática de Literatura e o processo da pesquisa são abordados na seção 4, a análise dos artigos selecionados, por meio da RSL, é apresentada na seção 5 e as considerações finais são descritas na seção 6 .

\section{Herança digital e Direito ao Esquecimento}

A herança digital e o Direito ao Esquecimento vêm sendo discutidos a partir dos limites entre o público e o privado e os direitos individuais inerentes à dignidade da pessoa humana, como a intimidade, a honra e a privacidade. Há, ainda, o direito à informação e a liberdade de expressão.

A Internet e as RSO são utilizadas em diversas áreas pelas pessoas que, ao armazenarem e compartilharem informações, levam à indagação sobre o que fazer com o acervo digital dos titulares e quem seriam seus herdeiros após ocorrer a inatividade nesse ambiente virtual. Para tanto, é importante apresentar o conceito de Direito ao Esquecimento:

O direito ao esquecimento é a faculdade que o titular de um dado pessoal tem para vê-lo apagado, suprimido ou bloqueado, pelo decurso do tempo, por ter cessado sua finalidade ou por afrontar seus direitos fundamentais. Trata-se de uma espécie de caducidade, em que a informação, pelo decurso do tempo, pela expiração da sua finalidade ou por sua proximidade com os direitos fundamentais afetos à personalidade, perece ou deveria perecer, ainda que por imposição de lei. (CHEHAB, 2015, p. 115). 
Nesse sentido, o Direito ao Esquecimento guarda estreita relação com a garantia da privacidade, a qual colide com a liberdade de expressão. Apesar de ter como objetivo proteger a intimidade das pessoas, ela atinge, especialmente, os dados pessoais que, na prática, devido aos novos valores trazidos pela tecnologia, refletem a privacidade dos dados digitais. Resumidamente, é um direito relacionado também ao conteúdo da Internet e ao resultado decorrente de sua disponibilidade.

Com base nessa ideia, Rodrigues e Oliveira (2015) destacam que a expressão a "internet não esquece" vem sendo disseminada na própria rede. Segundo as autoras, diante do papel crescente da internet na vida social, coletiva e política, talvez uma das principais interrogações, hoje, sobre o tema "memória" é que este se faz acompanhar, cada vez mais, do seu aparente reverso, o "esquecimento".

A fim de trazer respostas às novas demandas da sociedade pelo "esquecimento", na Alemanha, por exemplo, entendeu-se que a proteção constitucional da personalidade impede que a imprensa explore, por tempo indefinido, a pessoa do criminoso e sua privacidade, se for obstáculo a sua ressocialização (TEIXEIRA; PAULA, 2017).

Tal entendimento encena com maior força o direito ao esquecimento no palco das discussões da União Europeia (UE) onde em 25 de janeiro de 2012 a vice-presidente da Comissão Europeia e comissária encarregada de assuntos de justiça, Viviane Reding, anunciou o projeto de reforma geral das regras adotadas pela UE desde o último documento sobre proteção de dados do ano 1995. Entre as modificações introduzidas nas regras de 1995, encontra-se o direito ao esquecimento digital, com a finalidade de auxiliar "[...] os cidadãos a melhor gerir os riscos ligados à proteção dos dados na internet.” Por esse princípio, os cidadãos poderão "[...] obter a supressão de dados que lhes concernem se nenhum motivo legítimo justificar sua conservação." (UNIÃO EUROPÉIA, 2016, tradução nossa).

Em abril de 2016 um novo pacote de proteção de dados foi adotado com a finalidade de preparar a Europa para a era digital - Regulamento $\mathrm{n}^{\circ}$ 2016/679 do parlamento europeu e do conselho, mais conhecido como Regulamento Geral 
de Proteção dos Dados Pessoais da União Europeia (General Data Protection Regulation - GDPR), que entrou em vigor em maio de 2018 relativo à proteção das pessoas singulares no que diz respeito ao tratamento de dados pessoais e à livre circulação desses dados. Este regulamento é a lei mais relevante atualmente no cenário internacional e aborda a proteção das pessoas físicas em relação ao tratamento dos dados pessoais e a livre circulação desses dados. Tem como principal efeito ser de aplicação direta em toda a Europa, sem necessidade de ser incorporado pelo ordenamento jurídico de cada estado membro. Contempla os direitos de transparência, direitos de informação, direitos de acesso, direitos de retificação, direitos de eliminação ou direito ao esquecimento, limitação do tratamento dos dados, portabilidade dos dados e direito à oposição (UNIÃO EUROPEIA, 2016).

Esse regulamento, embora vigorando em território europeu, fez emergir em países que tem relações com comunidades da UE ou pretendem alcançar essa economia a necessidade de adequarem suas legislações no diz respeito à proteção de dados. O Brasil se enquadrou nesse contexto. Conforme destacam Ferreira, Marques e (2018, p. 3131-3132):

No Brasil os impactos do GDPR se fizeram sentir por meio da atualização de termos de uso de vários sites e aplicativos, tais como Facebook, Instagram, Google, Yahoo. Isso se deve ao fato que, mesmo sendo restrito à Europa, as empresas tiveram que se adequar à nova legislação para continuarem atuando nos países que compõe a União Europeia, o que levou à adoção de melhorias nas regras de outros países, inclusive do Brasil. Assim, as novas regras acabaram por afetar as transações referentes ao processamento de informações de cidadãos, não só da União Europeia, mas também de organizações localizadas fora da Europa.

Cabe salientar no entanto que o Brasil possui em seus dispositivos legais formas de regular a proteção de dados, principalmente quando se trata de direito ao esquecimento, como por exemplo, o Decreto-Lei n 2.848 do Código Penal que deixa claro em seu Art. $93^{\circ}$ que : “A reabilitação alcança quaisquer penas aplicadas em sentença definitiva, assegurando ao condenado o sigilo dos registros sobre o seu processo e condenação.” (BRASIL, 1940).

A Lei no 3.689 em seu Art. $748^{\circ}$ determina que "a condenação ou condenações anteriores não serão mencionadas na folha de antecedentes do 
reabilitado, nem em certidão extraída dos livros do juízo, salvo quando requisitadas por juiz criminal”. (BRASIL, 1941).

Os princípios fundamentais como a liberdade de expressão e o princípio da intimidade, estão garantidos na Lei no 11.105 :

Art. $5^{\circ}$ - Todos são iguais perante a lei, sem distinção de qualquer natureza, garantindo-se aos brasileiros e aos estrangeiros residentes no País a inviolabilidade do direito à vida, à liberdade, à igualdade, à segurança e à propriedade, nos termos seguintes: [...] IX - é livre a expressão da atividade intelectual, artística, científica e de comunicação, independentemente de censura ou licença; $\mathrm{X}$ - são invioláveis a intimidade, a vida privada, a honra e a imagem das pessoas, assegurado o direito a indenização pelo dano material ou moral decorrente de sua violação. [...]. (BRASIL, 1988).

O direito à intimidade é um direito personalíssimo com a característica básica de não expor elementos ou informações da vida íntima. A característica da intransmissibilidade se encontra positivada junto à Lei no 10.406 (BRASIL, 2002) que a torna impeditiva de transferência hereditária de direitos de personalidade, apesar de a tutela de muitos interesses relacionados à personalidade manter-se mesmo após a morte.

Avançando nas discussões sobre proteção de dados e direito ao esquecimento uma importante iniciativa se fez com a edição do Enunciado 531 da VI Jornada de Direito Civil, promovida pelo Conselho da Justiça Federal (CJF), em março de 2014. Enunciado preleciona que: "A tutela da dignidade da pessoa humana na sociedade da informação inclui o direito ao esquecimento". (BRASÍLIA, 2014).

Neste mesmo ano, outro dispositivo legal brasileiro - a Lei do Marco Civil da Internet (MCI), Lei no 12.965, sancionada em 23 de abril de 2014 foi considerada uma das legislações mais avançadas do mundo na regulação da internet e na garantia da neutralidade da rede e seu resultado foi proveniente de uma série de discussões iniciadas em anos anteriores já que no Congresso Nacional havia 26 propostas a respeito do tema. (MARQUES; KERR PINHEIRO, 2014).

Em seu artigo $7^{\circ}$, o MCI passa a tratar dos direitos dos usuários, nos quatro primeiros incisos- o direito à inviolabilidade da intimidade da vida 
privada, à inviolabilidade ao sigilo das comunicações e à inviolabilidade e ao sigilo das comunicações privadas armazenadas. No inciso VIII, do mesmo artigo, está expresso que é direito do usuário ter informações claras e completas sobre a coleta, uso, armazenamento, tratamento e proteção de seus dados pessoais que somente poderão ser utilizados para finalidades que (1) justifiquem sua coleta, (2) sejam lícitas e (3) estejam previstas em contrato. No inciso X, ainda do artigo $7^{\circ}$, foi incluído no MCI uma modulação do direito ao esquecimento. $\mathrm{O}$ artigo trata do direito à exclusão definitiva dos dados pessoais, a pedido do usuário titular, ao término das relações entre as partes.

Nesse contexto, observa- se que apesar dos atuais dispositivos legais brasileiros versarem sobre o assunto, havia necessidade de avançar na legislação específica sobre proteção de dados para se adequar à realidade da sociedade contemporânea, cujo contexto de fluxo informacional se ancora fortemente em novos recursos das tecnologias da informação e comunicação.

Sendo assim, em agosto de 2018 foi sancionada a Lei $\mathrm{n}^{\mathrm{o}} 13.709$ (lei geral de proteção de dados, LGPD), que altera o MCI e regulamenta o uso, a proteção e a transferência de dados pessoais que circulam na Internet, no âmbito brasileiro. Em seu escopo a lei possui 65 artigos distribuídos em 10 capítulos que dispõem sobre o tratamento, a proteção e a privacidade de dados pessoais em meios digitais. A lei indica que sua aplicação é destinada ao tratamento de dados pessoais pertencentes ou coletados de cidadãos localizados em território brasileiro (BRASIL, 2018).

No contexto deste artigo, com foco nas redes sociais on-line, preconizase o princípio da intimidade que, conforme relatado anteriormente, tem relação direta com o Direito ao Esquecimento, tendo em vista o artigo $5^{\circ}$ da Constituição Federal, que, em seu inciso $X$, declara invioláveis a honra e a imagem das pessoas, as quais constituem um direito à privacidade ou da intimidade.

Com a morte, finda-se a personalidade jurídica e, por conseguinte, a pessoa falecida não possuirá mais a aptidão para ser sujeito de direitos e obrigações na ordem jurídica, não sendo, portanto, titular de direitos de personalidade. No entanto, apesar da morte pôr fim à existência da pessoa física, 
ainda permanece o que se chama de memória do morto, por meio tanto do legado moral, quanto do legado digital deixados pela personalidade que um dia existiu no universo físico e no universo virtual.

$\mathrm{O}$ direito à honra é fundamental ao de cujus, pois, mesmo que este se encontre desprovido de vida, a sua memória se delonga no tempo, sendo digna de total zelo pelos legitimados, que buscarão protegê-la de acordo com a compreensão mais próxima do que um dia foi à honra para o de cujus.

Os e-mails de um usuário morto, apesar de haver decisões em contrário, não podem ser acessados, como forma de manter a intimidade e a reputação do de cujus, pois e-mail é, em regra, pessoal e as informações ali contidas são acessadas apenas pelo usuário. Isso difere de um perfil em uma rede social, onde as postagens são públicas e podem ser vistas e compartilhadas por outras pessoas. Entretanto, necessário se faz pensar em mecanismos que assegure o direito à privacidade dos dados pessoais, possibilitando ao usuário decidir e escolher a melhor forma de compartilhar suas informações, quer seja na atividade, quer seja na inatividade de seu perfil no âmbito das redes sociais online.

O Facebook, RSO norte-americana, tem a política de apresentar duas opções para a família. A primeira é transformar a página em memorial, deixando o acesso restrito a amigos confirmados pelo de cujus e mantendo apenas o conteúdo principal. A segunda opção é apagar todos os dados do usuário. Já a Google, empresa de tecnologia, apresenta alternativas, se o usuário preencher os termos, pode alertar o Google a respeito do momento em que a conta deve ser considerada inativa e, quando isso acontecer, se a empresa pode exclui-la automaticamente, para aqueles que desejam dar destinação específica aos dados armazenados nos servidores da empresa, numa espécie de testamento digital.

Seguindo nessa mesma direção, para os usuários que desejam deixar comunicações póstumas, alguns portais oferecem a possibilidade de programar mensagens que serão enviadas pelas redes sociais para pessoas previamente designadas. O usuário pode, ainda, programar sua última postagem em redes sociais como Facebook e Twitter, que será publicada pela empresa, uma vez que o falecimento seja confirmado. 


\section{Redes sociais on-line (RSO)}

Segundo Boyd e Ellison (2008), redes sociais são serviços baseados na web que permitem aos usuários construir um perfil público ou semipúblico dentro de um site específico, estabelecer uma lista com demais usuários para estabelecer conexão, além de rever e percorrer sua lista e as listas de outros usuários no sistema.

Com base nessa ideia, as redes sociais apresentam-se como ambientes para interação social e acesso informacional, na medida em que fornecem recursos para a troca de mensagens, compartilhamento de informações, conversas em tempo real, localização de pessoas e estabelecimento de vínculos entre seus usuários.

Com ênfase em uma abordagem sociológica, Marteleto (2001, p. 72) define redes sociais como "[...] um conjunto de participantes autônomos, unindo ideias e recursos em torno de valores e interesses compartilhados." Com o advento dos recursos da tecnologia da informação e comunicação (TIC) houve o surgimento das RSO, onde a partir do momento em que se cria um perfil pessoal, é possível se unir a amigos virtuais, participantes da rede, e assim, compartilhar pertences digitais como, por exemplo, fotos, imagens, mensagens e outras informações que vão, ao longo da experiência na rede, construindo bens componentes de uma herança digital que por sua vez, deve ter tratamento à luz da legalidade dos princípios fundamentais do Direito concernente à personalidade. Após anos de atividade em uma RSO, um usuário pode acumular conteúdo informacional que, de outra maneira, poderia se tornar totalmente restrita, devido ao volume e à quantidade de informações compartilhadas com outros usuários. Rodrigues e Oliveira (2015) apontam que informações disponibilizadas nas redes sociais, por obedecerem a uma nova lógica de tempo e espaço, alcançam uma abrangência de divulgação antes impensável, e ganham permanência, na medida em que são replicadas.

Para quantificar essa atividade no mundo virtual foi realizada uma pesquisa em 2014 pela DOMO, uma empresa de inteligência de dados criada pelo fundador da Omniture (empresa de análise de websites), a qual corresponde 
a Figura 1, contendo informações da atividade média de cerca de 2,1 bilhões de pessoas. $^{3}$

Figura 1 - Infográfico que apresenta os dados das atividades no mundo virtual

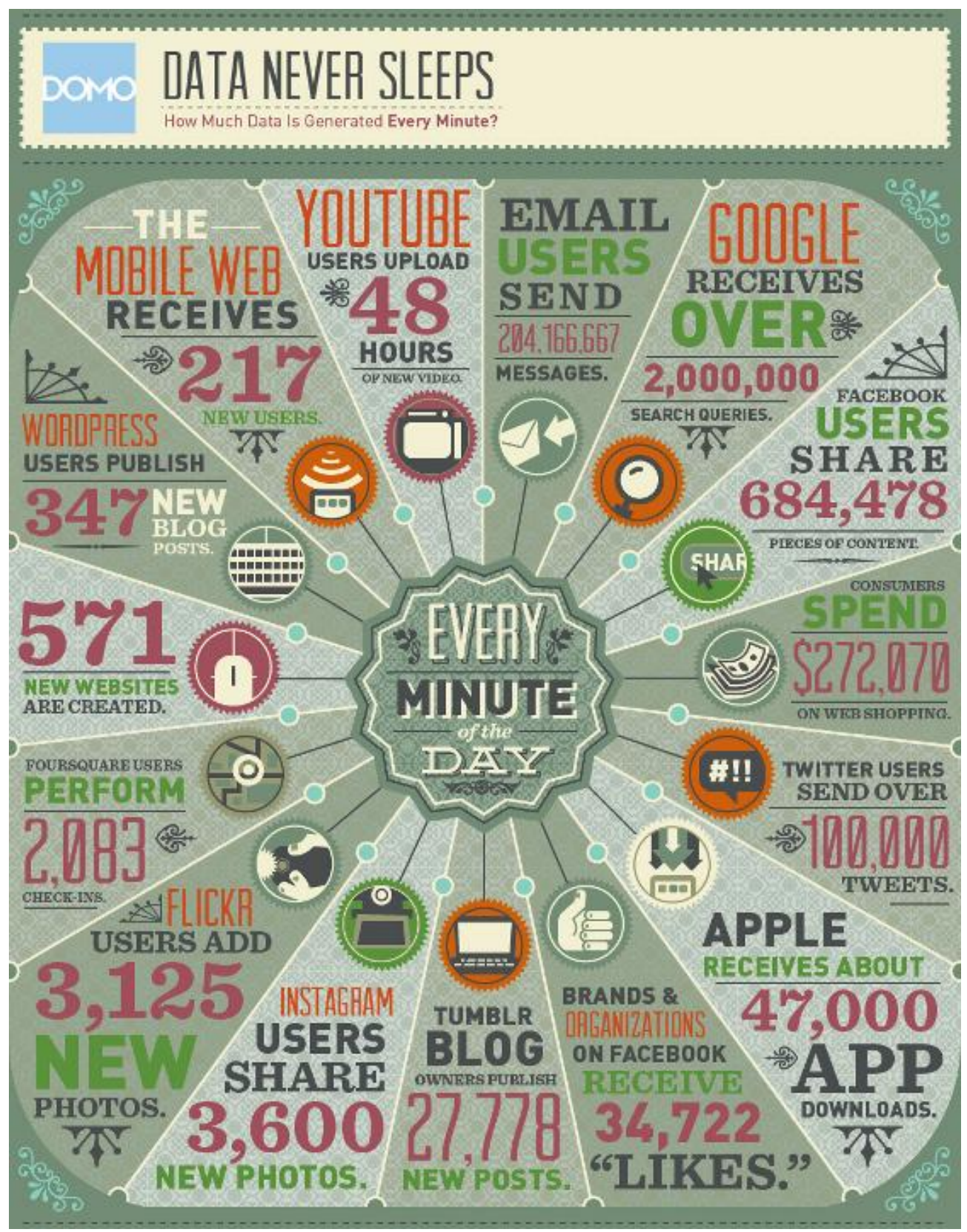

Fonte: DOMO (2014).

Conforme a pesquisa, em 60 segundos, usuários de e-mail enviam mais de 204 milhões de mensagens. No que diz respeito as redes sociais, os usuários do Facebook compartilham mais de 684 mil peças de conteúdo. Já os usuários do Twitter postam cerca de 100 mil tweets, enquanto os do Instagram 
compartilham cerca de 3.600 fotos. Por esses números, é possível observar a grande quantidade de conteúdo informacional que circula no universo da Internet, principalmente das RSO, e, nesse sentido, há forte tendência de crescimento ao longo do tempo, permitindo aos usuários disponibilizar ou recuperar informações a qualquer momento, mesmo decorrido um considerável espaço temporal.

Em razão disso, o Instituto do Direito ao Esquecimento, conforme aponta Moreira (2015), já compreendido pelo âmbito da proteção constitucional da privacidade, vem ganhando forte importância, ressurgindo como uma das principais discussões no campo do Direito Digital, que, por sua vez, aparece como uma nova área de estudo do Direito que visa regulamentar as interações sociais ocorridas no campo da tecnologia da informação.

\section{Revisão sistemática de literatura}

De acordo com o objetivo deste artigo, foi adotado como método de pesquisa a Systematic Literature Review (SLR), por ser um método bem definido para identificar, avaliar e interpretar estudos relevantes em relação a uma determinada questão de pesquisa ou área de estudo, conforme descrevem Mahdavi-Hezavehi, Galster e Avgeriou (2013). Nesse sentido, a SLR trouxe subsídios para responder à questão principal [QP] deste trabalho: Qual o atual cenário de pesquisa sobre o direito ao esquecimento e herança digital em redes sociais on-line? E para definir o foco dentro do contexto da resposta da [QP], foram elaboradas duas questões específicas [QE]:

[QE1]: Identificar estudos que abordam o Direito ao Esquecimento ou a Informação Digital com foco nos princípios de informação e de liberdade de expressão;

[QE2]: Identificar estudos que abordam o Direito ao Esquecimento ou a Informação Digital com foco nos princípios de intimidade e de privacidade.

Inicialmente, a pesquisa fez uso da busca manual por trabalhos publicados a partir de 2014, tendo em vista a promulgação do Marco Civil da Internet no Brasil. As bases definidas naquele momento foram Ebsco, Emerald, Scielo e Spell, por serem considerados repositórios de grande repercussão no 
meio acadêmico, com pesquisas de qualidade relacionadas a diversas áreas do conhecimento.

Os termos de busca utilizados nesses repositórios foram: "sistemas de informação", "Direito ao Esquecimento" e a combinação entre eles. Como os resultados foram insatisfatórios, uma vez que não foram localizados estudos que integrassem ambos os termos, optou-se por uma nova procura com os seguintes termos de pesquisa: "Redes sociais on-line", "Direito ao Esquecimento", "Herança digital" e a combinação entre eles. Os resultados também não foram expressivos quando se buscou pela combinação entre os termos.

Assim, optou-se por mudar o repositório e uma nova busca foi realizada em revistas acadêmicas da área do Direito do Portal Sucupira, cujos qualis fossem A1, A2 e B1 ${ }^{4}$. Foram consideradas as publicações do período compreendido entre 2013 e 2016 por se tratar de um período onde aconteceram as discussões e a promulgação do MCI no Brasil.

Em função do repositório ser específico da área de Direito, optou-se por alterar as palavras de busca, na tentativa de ampliar os resultados. Assim, considerou-se que os estudos foram satisfatórios, tendo em vista o retorno de 21 artigos por meio da utilização dos seguintes termos de busca: "Direito", "Privacidade" e "Proteção de dados".

Para alcançar a seleção dos artigos adotou-se como metodologia três etapas de filtragem:

a) eliminação por título;

b) eliminação por leitura do tipo skimming;

c) leitura completa com análise de conteúdo;

As duas primeiras etapas ocorreram quando o conteúdo do artigo não estabelecia relação direta com o objetivo da pesquisa, o que resultou na eliminação de três artigos e, a última, ocasionou a eliminação de mais dois artigos que apesar de terem no título vínculo com o tema estudado não possibilitavam a classificação de acordo com os objetivos proposto neste trabalho, resultando assim, na seleção de 16 (dezesseis) artigos para a RSL.

$\mathrm{Na}$ terceira etapa, onde se fez a leitura completa dos 16 artigos, foi definido que cada trabalho seria classificado quanto ao princípio adotado pelo 
Direito ao Esquecimento - princípios da informação e da liberdade de expressão (Inf. e LE) e princípios de intimidade e da privacidade (Int. e Priv.). O Quadro 1 apresenta os autores, os títulos e os repositórios desses artigos selecionados durante a revisão sistemática, bem como o enquadramento de cada um deles na classificação adotada.

Quadro 1 - Artigos selecionados de acordo com os princípios do Direito ao Esquecimento

\begin{tabular}{|c|c|c|c|c|}
\hline Autor(es) & Título & Repositório & $\begin{array}{l}\text { Princ. } \\
\text { Inf. e } \\
\text { LE }\end{array}$ & $\begin{array}{l}\text { Princ. } \\
\text { Int. e } \\
\text { Priv. }\end{array}$ \\
\hline $\begin{array}{l}\text { [Barros e } \\
\text { Nasciment } \\
\text { o, 2015] }\end{array}$ & $\begin{array}{c}\text { OS FLUXOS INFORMACIONAIS E O } \\
\text { CONSTITUCIONALISMO - A FORÇA } \\
\text { DA INTERNET E A CONSECUÇÃO } \\
\text { DE DIREITOS: um olhar sobre o papel } \\
\text { das TICs e Mídias Digitais na } \\
\text { Contemporaneidade }\end{array}$ & $\begin{array}{l}\text { Democracia } \\
\text { Digital e } \\
\text { Governo } \\
\text { Eletrônico }\end{array}$ & & \\
\hline $\begin{array}{l}\text { [Cella e } \\
\text { Rosa, } \\
\text { 2013] }\end{array}$ & $\begin{array}{c}\text { CONTROLE SOCIAL E } \\
\text { NECESSIDADE DE PROTEÇÃO DE } \\
\text { DADOS PESSOAIS }\end{array}$ & $\begin{array}{l}\text { Democracia } \\
\text { Digital e } \\
\text { Governo } \\
\text { Eletrônico }\end{array}$ & & \\
\hline $\begin{array}{l}\text { [Garcia e } \\
\text { Silva, } \\
\text { 2012] }\end{array}$ & $\begin{array}{l}\text { APONTAMENTOS SOBRE O } \\
\text { ARMAZENAMENTO DE REGISTROS } \\
\text { DA INTERNET SOB O VIÉS DA } \\
\text { LIMITAÇÃO DO DIREITO GERAL DE } \\
\text { LIBERDADE PELA ATIVIDADE } \\
\text { NORMATIVA }\end{array}$ & $\begin{array}{l}\text { Democracia } \\
\text { Digital e } \\
\text { Governo } \\
\text { Eletrônico }\end{array}$ & & \\
\hline $\begin{array}{l}\text { [Moraes, } \\
\text { 2013] }\end{array}$ & $\begin{array}{l}\text { MARCO CIVIL DA INTERNET NO } \\
\text { BRASIL: das origens dos Direitos } \\
\text { Fundamentais aos propósitos do Direito } \\
\text { de Acesso à Informação }\end{array}$ & $\begin{array}{l}\text { Democracia } \\
\text { Digital e } \\
\text { Governo } \\
\text { Eletrônico }\end{array}$ & & \\
\hline $\begin{array}{l}\text { [Santos, } \\
\text { Andrade e } \\
\text { Novaes, } \\
\text { 2014] }\end{array}$ & $\begin{array}{l}\text { SINERGIA NA RESOLUÇÃO DE } \\
\text { LITÍGIOS EM LINHA E A } \\
\text { NECESSIDADE DE PROTEÇÃO DA } \\
\text { PRIVACIDADE E DOS DADOS } \\
\text { PESSOAIS }\end{array}$ & $\begin{array}{l}\text { Democracia } \\
\text { Digital e } \\
\text { Governo } \\
\text { Eletrônico }\end{array}$ & & \\
\hline $\begin{array}{l}\text { [ Vaz, } \\
\text { 2011] }\end{array}$ & $\begin{array}{c}\text { NEUTRALIDADE NA REDE, } \\
\text { PROTEÇÃO DE DADOS PESSOAIS E } \\
\text { MARCO REGULATÓRIO DA } \\
\text { INTERNET NO BRASIL }\end{array}$ & $\begin{array}{l}\text { Democracia } \\
\text { Digital e } \\
\text { Governo } \\
\text { Eletrônico }\end{array}$ & & \\
\hline $\begin{array}{l}\text { [Oliveira, } \\
\text { Barros e } \\
\text { Goulart, } \\
\text { 2016] }\end{array}$ & $\begin{array}{c}\text { AS TECNOLOGIAS DA } \\
\text { INFORMAÇÃO E COMUNICAÇÃO } \\
\text { NA (DES)CONSTRUÇÃO DAS } \\
\text { RELAÇÕES HUMANAS } \\
\text { CONTEMPORÂNEAS: implicações do } \\
\text { uso do aplicativo Tinder }\end{array}$ & $\begin{array}{l}\text { Revista } \\
\text { Brasileira de } \\
\text { Direito }\end{array}$ & & \\
\hline
\end{tabular}




\begin{tabular}{|c|c|c|c|}
\hline $\begin{array}{l}\text { [Diniz, } \\
\text { 2017] }\end{array}$ & $\begin{array}{c}\text { UMA VISÃO CONSTITUCIONAL E } \\
\text { CIVIL DO NOVO PARADIGMA DA } \\
\text { PRIVACIDADE: o direito a ser } \\
\text { esquecido }\end{array}$ & $\begin{array}{l}\text { Revista } \\
\text { Brasileira de } \\
\text { Direito }\end{array}$ & \\
\hline $\begin{array}{l}\text { [Nascimen } \\
\text { to e } \\
\text { Rodrigues } \\
\text {, 2013] }\end{array}$ & $\begin{array}{l}\text { A SOCIEDADE INFORMACIONAL } \\
\text { EM XEQUE: PRINCÍPIO DA } \\
\text { PUBLICIDADE VERSUS DIREITO À } \\
\text { INTIMIDADE E A LEI 12.527/11 }\end{array}$ & $\begin{array}{l}\text { Revista de } \\
\text { Direitos } \\
\text { Fundamentais } \\
\text { e Democracia }\end{array}$ & \\
\hline $\begin{array}{l}\text { [Machado, } \\
\text { 2014] }\end{array}$ & $\begin{array}{c}\text { A EXPANSÃO DO CONCEITO DE } \\
\text { PRIVACIDADE E A EVOLUÇÃO NA } \\
\text { TECNOLOGIA DE INFORMAÇÃO } \\
\text { COM O SURGIMENTO DOS BANCOS } \\
\text { DE DADOS }\end{array}$ & $\begin{array}{l}\text { Revista da } \\
\text { AJURIS }\end{array}$ & \\
\hline $\begin{array}{l}\text { [Baião e } \\
\text { Gonçalves } \\
\text {, 2014] }\end{array}$ & $\begin{array}{l}\text { A GARANTIA DA PRIVACIDADE NA } \\
\text { SOCIEDADE TECNOLÓGICA: um } \\
\text { imperativo à conscientização do princípio } \\
\text { da dignidade da pessoa humana }\end{array}$ & $\begin{array}{c}\text { Civilistica.co } \\
\mathrm{m}\end{array}$ & \\
\hline $\begin{array}{l}\text { [Jereissat } \\
\text { e Dias, } \\
\text { 2017] }\end{array}$ & $\begin{array}{c}\text { LEGITIMIDADE ATIVA DOS } \\
\text { SUCESSORES E DO CÔNJUGE OU } \\
\text { COMPANHEIRO SOBREVIVENTE } \\
\text { PARA IMPETRAÇÃO DO HABEAS } \\
\text { DATA SOB A ÓTICA DA } \\
\text { PRESERVAÇÃO DA PRIVACIDADE } \\
\text { DO MORTO }\end{array}$ & $\begin{array}{c}\text { Civilistica.co } \\
\mathrm{m}\end{array}$ & \\
\hline $\begin{array}{l}\text { [Pezzella } \\
\text { e Ghisi, } \\
\text { 2013] }\end{array}$ & $\begin{array}{l}\text { PRIVACIDADE NA SOCIEDADE DA } \\
\text { INFORMAÇÃO: controle e direito ao } \\
\text { esquecimento em espaços públicos }\end{array}$ & $\begin{array}{l}\text { Revista da } \\
\text { AJURIS }\end{array}$ & \\
\hline $\begin{array}{l}\text { [Hachem } \\
\text { e Gussoli, } \\
\text { 2015] }\end{array}$ & $\begin{array}{l}\text { A QUEBRA DE SIGILO BANCÁRIO } \\
\text { POST MORTEM EM INQUÉRITO } \\
\text { POLICIAL: entre a proteção dos direitos } \\
\text { fundamentais à intimidade e à privacidade } \\
\text { e o interesse público de persecução penal. }\end{array}$ & $\begin{array}{c}\text { Revista de } \\
\text { Direito } \\
\text { Administrativ } \\
\text { o \& } \\
\text { Constituciona } \\
1\end{array}$ & \\
\hline $\begin{array}{l}\text { [Cancelier } \\
\text { e Pilati, } \\
\text { 2017] }\end{array}$ & $\begin{array}{l}\text { PRIVACIDADE, PÓS-MODERNIDADE } \\
\text { JURÍDICA E GOVERNANÇA } \\
\text { DIGITAL: o exemplo do marco civil da } \\
\text { internet na direção de um novo direito }\end{array}$ & $\begin{array}{l}\text { Espaço } \\
\text { Jurídico } \\
\text { Jornal of Law }\end{array}$ & \\
\hline $\begin{array}{l}\text { [Acunha, } \\
\text { 2016] }\end{array}$ & $\begin{array}{c}\text { DEMOCRACIA E } \\
\text { TRANSCONSTITUCIONALISMO: } \\
\text { "direito ao esquecimento", } \\
\text { extraterritorialidade e conflito entre } \\
\text { ordens jurídicas }\end{array}$ & $\begin{array}{c}\text { Revista } \\
\text { Direito GV }\end{array}$ & \\
\hline
\end{tabular}

Fonte: Elaborado pelos autores.

\section{Análise dos resultados}


A partir dos artigos selecionados, foi possível responder as questões de pesquisa propostas neste trabalho, conforme apresentado a seguir.

\section{1 [QE1] Identificar estudos que abordam o Direito ao Esquecimento ou a} informação digital com foco nos princípios de informação e liberdade de expressão

Com esse recorte, Barros e Nascimento (2015) descrevem as TICs como legítimos instrumentos para viabilizar a busca e a efetivação de direitos e propiciar o exercício amplo da cidadania por meio virtual. As RSO são exemplos de TICs e, nesse contexto, apresentam-se como balizas informacionais e ambientes favoráveis para o empoderamento do cidadão, oportunizando novas prerrogativas diante do Estado, considerando que "[...] a Internet é um dos mais revolucionários meios tecnológicos, uma vez que permite a comunicação entre usuários de todo o mundo pela interconexão de redes."

Nesse sentido, os autores consideram que a Internet trouxe diversas modificações positivas permitindo, em escalas globais, o exercício da liberdade de expressão e de pensamento como possibilidade para formação e consolidação da cidadania, na medida em que por meio do direito à informação, [...], pressupõe o fomento, criação, edição e difusão da informação por todos os indivíduos [...].

Entretanto, para Garcia e Silva (2012), o direito geral de liberdade encontra os limites estritos de seu exercício na norma posta constitucionalmente, uma vez que a atividade normativa poderia implicar na restrição indevida do direito à liberdade em prejuízo ao caráter liberalista e democrático da rede. Segundo os autores, muitas vezes a interferência governamental para regramento de uma conduta pode ser uma ofensa à direitos estabelecidos - “[...] notadamente o direito de liberdade que é cada vez mais restringido quanto mais o Estado agiganta-se em sua atividade normativa deixando menor espaço para a escolha individual de conduta." (GARCIA E SILVA, 2012, p. 29).

Na visão de Moraes (2013), o contexto histórico brasileiro, marcado pelo surgimento de ideias revolucionárias da Revolução Francesa e a consagração das liberdades expressas na Constituição de 1988, deram origem aos direitos fundamentais inspirados nessas ideias de liberdade e igualdade essenciais ao 
conceito de dignidade da pessoa humana. Segundo o autor, o aporte histórico inicial deu origem às clássicas definições sobre três primeiras gerações, onde a primeira englobava direitos civis, direitos políticos e direitos contra os arbítrios do Estado. Já a segunda geração fez surgir a apropriação de direitos sociais, econômicos e culturais. Por fim, no século XX, passam a ser reconhecidos os direitos à educação, à saúde, à previdência pública e ao trabalho. Essa terceira geração, descreve o autor, originou novas perspectivas dos direitos fundamentais, com estudos de novas classificações, discussões e entendimentos sobre uma possível quarta ou até mesmo quinta geração destes direitos. Neste sentido, a liberdade relacionada ao cerne da sociedade tem como consequência a socialização, a circulação e o acesso à informação, com o intuito de dar continuidade à evolução do conhecimento em um contexto democrático.

Partindo desse pressuposto, Moraes (2013) aborda, ainda, a importância do Marco Civil da Internet que visa adotar diretrizes na esfera civil, permitindo disciplinar direitos e liberdades dos cidadãos brasileiros dentro dos valores da sociedade contemporânea, influenciada pelas tecnologias das redes informáticas. Nesse sentido, ele aborda também a Lei de Acesso à Informação 12.527/2011 que em seu objetivo, visa prover maior participação dos cidadãos brasileiros por meio de acesso à informação pública, onde esse acesso é a regra, e o sigilo, a exceção.

\section{2 [QE2] Identificar estudos que abordam o Direito ao Esquecimento ou a} informação digital com foco nos princípios da intimidade e de privacidade

Por esse prisma, Cella e Rosa (2013) relacionam o surgimento da Internet com a expansão das possibilidades de comunicação que suscita a explosão de muitas questões ligadas à privacidade.

Segundo os autores, ao longo da história a sociedade vivenciou a evolução dos meios e das técnicas de comunicação, que, por sua vez, trataram do tema privacidade a luz dos recursos e mecanismos de cada época. Eles consideram difícil cristalizar em um único conceito a problemática da privacidade, mas destacam que ela sempre foi diretamente condicionada pelo contexto tecnológico de cada época e sociedade. Corroboram com a hipótese de 
que o advento de estruturas jurídicas e sociais que tratam do problema da privacidade são respostas diretas a uma nova condição da informação, determinada pela tecnologia.

Ainda segundo Cella e Rosa (2013), a Internet possibilitou a inserção nas redes sociais que conectam o mundo e possibilitam acesso e interação com outras culturas, realidades, costumes, enfim, a tudo o que seja necessário e procurado por cada pessoa. Em termos de tecnologia, foi um avanço sem precedentes. Entretanto, os autores alertam que a necessidade psicológica de inserção social faz com que os indivíduos divulguem informações confidenciais, correndo riscos em termos de segurança. Enfatizam a importância dos princípios que propõe segurança aos indivíduos e seus dados segundo a Organização e Cooperação para Desenvolvimento Econômico (OCDE) e que podem ser identificados em diversas leis, tratados e convenções como forma de diretivas para fornecer soluções ao problema da proteção de dados pessoais.

A abordagem de Santos, Andrade e Novais (2014) corrobora com a mesma ordem regulatória prevista nas diretrizes da OCDE para proteção da privacidade e dos fluxos transfronteiriços de dados pessoais. Os autores realizaram o trabalho para analisar a relevância, a aplicabilidade e a adequação da legislação atinente à privacidade e proteção de dados face aos emergentes desafios de ambientes inteligentes, os quais são caracterizados como ambientes que incorporam tecnologia dotada de capacidade e poder de processamento computacional e aportada de dispositivos observáveis e externos. Além disso, estas tecnologias captam informação do ambiente ou informação contextual, de forma a ser processada para, posteriormente, responder às necessidades dos seus utilizadores. Nesse contexto, os autores alertam para a necessidade de repensar questões relacionadas com a identidade e a autodeterminação da pessoa humana, a privacidade, a proteção de dados, a transparência dos sistemas, o consentimento das partes e a finalidade da recolha de dados. Na apreciação dos requisitos atinentes à privacidade e proteção de dados que são pertinentes no contexto de computação ubíqua, Santos, Andrade e Novais (2014) reforçam a necessidade de espaços de normatividade ou "pluralismo normativo", incluindo o direito, a tecnologia, as partes interessadas no domínio das TICs e a sociedade, 
os quais devem ser proativos de forma que a legislação relativa à privacidade e proteção de dados possa evoluir para acomodar os novos desafios colocados pelos ambientes inteligentes.

Nesse sentido, Vaz (2011) aponta um dos grandes desafios do direito: se mostrar apto a responder a novidade proposta pela tecnologia com a reafirmação de seu valor fundamental - a pessoa humana - e, ao mesmo tempo, fornecer a segurança necessária para que haja previsibilidade. Segundo $\operatorname{Amaral}^{6}$ (2002, p. 5 apud VAZ, 2011, p. 153):

Vivemos numa sociedade complexa, pluralista e fragmentada, para a qual os tradicionais modelos jurídicos já se mostraram insuficientes, impondo-se à ciência do direito a construção de novas e adequadas 'estruturas jurídicas de resposta', capazes de assegurar a realização da justiça e da segurança em uma sociedade em rápido processo de mudança.

Na visão da autora, por meio da proteção de dados pessoais, as garantias de princípios relacionados com a privacidade passam a ser vistos em uma ótica mais abrangente pela qual outros interesses devem ser considerados e abranger as diversas formas de controle tornadas possíveis com a manipulação de dados pessoais.

Para Oliveira, Barros e Goulard (2016) a sociedade está vivenciando uma era de transição midiática e de transformação tecnológica que passam a atacar diversos âmbitos, a seara social e de relacionamentos humanos no concernente à imbricada construção e à edificação de relações e interlocuções entre os pares. Os autores alertam para os potenciais riscos que o contato virtual, estabelecido por meio das redes sociais, podem acarretar algumas circunstâncias, principalmente com relação às informações pessoais e de cunho privado.

Diniz (2017, p.12) aborda a lei do Marco Civil da Internet (Lei 12.965/2014) especificamente o art. $7^{\circ}$ inciso X, onde é tratado, tanto a liberdade de expressão, quanto a proteção da privacidade e dados pessoais:

$\mathrm{O}$ acesso à internet é essencial ao exercício da cidadania e ao usuário é assegurado o direito a exclusão definitiva dos dados pessoais que tiver fornecido a determinada aplicação de internet, a 
seu requerimento, ao término da relação entre as partes, ressalvadas as hipóteses de guarda obrigatória de registros previstas nesta lei.

A autora enfatiza que uma tomada de consciência sobre o direito a ser esquecido, como um novo paradigma da privacidade, será uma das maiores conquistas do século XXI em busca de solidariedade e do respeito à dignidade humana.

Na abordagem de Nascimento e Rodrigues (2013) há ênfase, tanto ao direito à informação, quanto ao direito à privacidade para tratar especificamente da determinação do Supremo Tribunal Federal sobre a divulgação pela Internet dos dados de vencimentos de todos os servidores púbicos com base na Lei $\mathrm{n}^{\circ}$ 12.527/2011, denominada Lei de Acesso à Informação. Os autores descrevem que, posteriormente, algumas decisões, com base no direito à intimidade, proibiram tal divulgação. Eles reforçam a importância de haver uma convivência harmônica entre os direitos, uma vez que o direito fundamental à informação não pode se sobrepor ao direito fundamental à inviolabilidade da vida privada e intimidade, e vice-versa.

Hachem e Gussoli (2015) compartilham a mesma ideia ao descreverem que a colisão entre princípios deve ser solucionada mediante a técnica da ponderação. Se dois princípios, num determinado caso, indicarem caminhos opostos a serem seguidos, não há que se declarar a invalidade de um deles, nem incluir uma cláusula de exceção. Um irá ceder passo ao outro, conforme o peso exercido por cada um deles naquelas circunstâncias.

No estudo de Machado (2014), a ênfase é dada ao direito à privacidade, uma vez que, pela visão da autora, a evolução dos recursos tecnológicos determina uma nova abordagem a esse direito e à proteção dos dados. Ela considera que com a evolução das tecnologias da informação e comunicação, a privacidade não mais poderia ser analisada apenas pelo aspecto do recato e do isolamento, na medida em que a informação passou a ser um bem valioso, tanto para o Poder Público como para as empresas privadas, isto porque percebeu-se que a coleta e o tratamento de informações pessoais em bancos de dados poderiam ser bastante proveitosos, principalmente do ponto de vista econômico. 
Compartilhando desse argumento, Baião e Gonçalves (2014) apresentam uma reinterpretação do conceito de privacidade dada por Stefano Rodotá, enriquecendo a definição tradicional como "direito de ficar só" com o direito à "autodeterminação informativa", conceito que engloba o que será revelado; direito ao esquecimento, em resumo, o direito de determinar a maneira de construir a própria esfera particular.

O estudo de Jereissat e Dias (2017) aborda a legitimidade ativa para impetração do habeas data que caberá apenas ao sujeito que tiver informações acerca de si em registros de bancos de dados de entidades governamentais ou de caráter público, pois o consideram um direito personalíssimo que "morre com o titular", garantindo assim, a intimidade e a privacidade.

Nos dias de hoje, segundo Pezzella e Ghisi (2013), o estudo do direito à privacidade não pode ignorar a sociedade da informação, realidade permeada pelo imprescindível trânsito de informações imbricadas com a aplicação de tecnologias. A utilização de informações e tecnologias, assim como sua reprodução e replicação, é uma constante que caracteriza a sociedade da informação e as relações sociais que nela se estabelecem, de tal modo que corpo social e pessoas individualmente consideradas por esta sociedade tornam-se dependentes da dinâmica tecnológica informacional continuamente autorredefinadora. Os autores reforçam que em todos os casos, consentimento expresso e o interesse público legítimo e justificado são critérios que podem modular o direito ao esquecimento da passagem da pessoa em espaços públicos.

Cancelier e Pilati (2017) destacam que há cerca de 60 anos a possibilidade de uma sociedade constantemente vigiada por câmeras e telas onipresentes, sem espaços para se esconder, na qual todos recebiam constantemente notícias - verdadeiras ou não - sobre a vida de todos, deveria parecer aterrorizante. No entanto, décadas depois nos deparamos com uma privacidade completamente transfigurada, se comparada com aquele momento, e que justifica sua transformação justamente com a democratização e a liberdade da informação.

Por fim, o direito ao esquecimento é tratado por Acunha (2016) dentro da disposição de direito fundamental de inegável valor jurídico e, até mesmo, 
moral. O autor afirma que certamente, a pretensão de respeitar a inviolabilidade da vida privada dos indivíduos é um dos mais importantes objetivos do direito e por isso a produção de normas e decisões nesse contexto tem que ser posta em discussão.

\section{Considerações finais}

Este artigo apresentou uma revisão sistemática de literatura para verificar o atual panorama de estudos do Direito ao Esquecimento e herança digital de usuários de redes sociais on-line. Pode-se inferir que os princípios da Informação e liberdade de expressão, tão importantes quanto os da intimidade e privacidade, estão ganhando espaço de atuação frente às possibilidades proporcionadas pela Internet, principalmente, pelas redes sociais on-line, cujo ambiente de acesso e propagação se faz de maneira ampla, popular e, muitas vezes, econômica. Nesse sentido, discussões e estudos estão sendo voltados para a análise do tratamento dessas informações que, por sua vez, esbarra nos princípios relacionados à intimidade e privacidade, sendo estas as áreas com maior ênfase de pesquisa e estudos.

Se por um lado o acesso a informação e a liberdade de expressão são vistos com a prerrogativa do indivíduo frente ao Estado, a intimidade e a privacidade detém a prerrogativa do indivíduo frente à sociedade que, por sua vez, experimenta na contemporaneidade, avanços tecnológicos e mudanças comportamentais capazes de alterar e buscar respostas e garantias à luz da ciência do Direito.

Partindo desse pressuposto, entende-se que o cerne das discussões na sociedade contemporânea devem continuar enfocando os princípios relacionados à intimidade e privacidade, uma vez que pelo próprio texto constitucional a vida privada compreende dois aspectos, um voltado para a vida exterior, que envolve o indivíduo nas interações sociais e nas atividades públicas, podendo ser objeto de pesquisa e divulgação de terceiros, considerando que é pública; e outro aspecto voltado para a vida interior, que refere à própria pessoa, sobre sua família e amigos (MOREIRA, 2015). É a essa vida interior a que a Constituição se refere como inviolável no artigo $5^{\circ}$, inciso $\mathrm{X}$, descrito anteriormente. 
As RSO estão permeadas de interações sociais onde a exposição de informações sobre a própria pessoa, família e amigos se faz de maneira natural, facilitada pelos recursos tecnológicos. Nesse emaranhado de conteúdo, tornamse relevantes os estudos sob a perspectiva interdisciplinar em que a Ciência da Computação alie-se às Ciências Sociais e a Ciência do Direito para analisar e responder, com o devido tratamento, o acervo informacional digital produzido e deixado como herança às famílias daqueles que foram, um dia, ativos e presentes nas redes sociais on-line.

\section{Financiamento}

Os autores agradecem à Fundação de Amparo à Pesquisa do Estado de Minas Gerais (FAPEMIG) pelo apoio concedido para realização desta pesquisa.

\section{Referências}

ACUNHA, Fernando José Gonçalves. Democracia e transconstitucionalismo: "Direito Ao Esquecimento", extraterritorialidade e conflito entre ordens jurídicas. Revista Direito GV, São Paulo, v.12, n. 3, p. 748-775. set./dez. 2016.

BAIÃO, Kelly Cristine Sampaio; GONÇALVES, Kalline Carvalho. A garantia da privacidade na sociedade tecnológica: um imperativo à concretização do princípio da dignidade da pessoa humana. Revista Eletrônica de Direito Civil, [s.l.], a. 3, n. 2, p. 1-24, 2014.

BARROS, Bruno Mello Corrêa; NASCIMENTO, Valéria Rodrigues. Os fluxos informacionais e o constitucionalismo - a força da internet e a consecução de direitos: um olhar sobre o papel das Tics e mídias digitais na contemporaneidade. Revista Democracia Digital e Governo Eletrônico, Florianópolis, v.13, n. 13, p 149-173, 2015.

BOYD, Danah, M.; ELLISON, Nicole. B. Social network sites: definition, history, and scholarship. Journal of Computer - Mediated

Communication, [s.l.], v. 13, n. 1, p. 210-230, out. 2008.

BRASIL. Lei $n^{\circ} 13.709$, de 14 de agosto de 2018. Dispõe sobre a proteção de dados pessoais e altera a Lei $\mathrm{n}^{\circ}$ 12.965, de 23 de abril de 2014 (Marco Civil da Internet). Diário Oficial [da] União, Brasília, 15 ago. 2018.

Lei Geral de Proteção de Dados Pessoais (LGPD), redação dada pela Lei ${ }^{\circ}$ 13.853, de 2019. 
BRASIL. Lei $\mathrm{n}^{\circ} 10.406$, de 10 de janeiro de 2002. Institui o código civil. Diário Oficial [da] União, Brasília, de 11 jan. 2002.

BRASIL. Lei $\mathrm{n}^{\circ} 2.848$, de 7 de dezembro de 1940. Dispõe sobre o código penal. Diário Oficial [da] União, Brasília, 31 dez. 1940.

BRASIL. Lei n ${ }^{\circ} 3.689$, de 3 de outubro de 1941. Dispõe sobre o código de processo penal. Diário Oficial [da] União, Brasília, 13 set. 1941. Retificado no DOU de 24 set. 1941.

BRASIL. Lei ${ }^{\circ} 11.105$ de 5 de outubro de 1988. Dispõe sobre a constituição da república federativa do Brasil. Diário Oficial [da] União, Brasília, 1988.

BRASILIA (DF). Enunciado 531. Brasília, 2014. VI Jornada de Direito Civil.

CANCELIER, Mikhail Vieira de Lorenzi; PILATI, José Isaac. Privacidade, pósmodernidade jurídica e governança digital: o exemplo do marco civil da internet na direção de um novo direito. Revista Espaço Jurídico Journal of Law, Joaçaba, v. 18, n. 1, p. 65-82, jan./abr. 2017

CELLA, José Renato Gaziero; ROSA, Luana Aparecida dos Santos. Controle social e necessidade de proteção de dados pessoais. Revista Democracia Digital e Governo Eletrônico, Florianópolis, v. 2, n. 9, p. 158171, 2013.

CHEHAB, Gustavo Carvalho. A privacidade ameaçada de morte. São Paulo: LTr, 2015.

COSTA FILHO, Marco Aurélio Farias. Herança digital: valor patrimonial e sucessão de bens armazenados virtualmente. Revista Jurídica da Seção Judiciária de Pernambuco, [s.l.], n. 9, p. 187-215, 2016.

DINIZ, Maria Helena. Uma visão constitucional e civil do novo paradigma da privacidade: o direito a ser esquecido. Revista Brasileira de Direito, Passo Fundo, v. 13, n. 2, p. 7-25, mai./ago. 2017.

DOMO. Data never sleeps: how much data is generated every minute? 2014. 1 imagem. Infográfico resumo atividade global na Internet.

EMARKETER. [Número dos usuários das redes sociais]. 2016. 1 tabela.

FERREIRA, Daniela Assis Alves; MARQUES, Rodrigo Moreno; NATELE, Alexandra; A política de informação na arena da privacidade de dados pessoais. In: ENCONTRO NACIONAL DE PESQUISA EM CIÊNCIA DA INFORMAÇÃO, 19., 2018, Londrina. Anais [...]. Londrina: Ancib, 2018. p. 3119-3138.

GARCIA, Bruna Pinotti; SILVA, André Barboza da. Apontamentos sobre o armazenamento de registros da internet sob o viés da limitação do direito 
geral de liberdade pela atividade normativa. Revista Democracia Digital e Governo Eletrônico, Florianópolis, v. 2, n. 7, p. 1-31, 2012.

HACHEM, Daniel Wunder; GUSSOLI, Felipe Klein. A quebra de sigilo bancário post mortem em inquérito policial: entre a proteção dos direitos fundamentais à intimidade e à privacidade e o interesse público de persecução penal. A\&C - Revista De Direito Administrativo \& Constitucional, Belo Horizonte, v. 15, n. 60, p. 149-177, abr./jun. 2015.

JUSBRASIL. Direitos personalíssimos. c2019.

MAHDAVI-HEZAVEHI, Sara; GALSTER, Matthias, AVGERIOU, Paris. Variability in quality attributes of service-based software systems: a systematic literature review. Information and Software Techology, Groningen, v. 55, i. 2, p. 320-343, fev. 2013.

JEREISSATI, Régis Gurgel do Amaral; DIAS, Eduardo Rocha. Legitimidade ativa dos sucessores e do cônjuge ou companheiro sobrevivente para impetração do habeas data sob a ótica da preservação da privacidade do morto. Revista Eletrônica de Direito Civil, [s.l.], a. 6, n. 1, p. 1-43, 2017.

MACHADO, Joana de Moraes Souza. A expansão do conceito de privacidade e a evolução na tecnologia de informação com o surgimento dos bancos de dados. Revista da Associação dos Juízes do Rio Grande do Sul, Porto Alegre, v. 41, n. 134, p. 337-363, jun. 2014.

MARQUES, Rodrigo Moreno; KERR PINHEIRO, Marta Macedo. Marco Civil da Internet: uma análise sob a ótica da razão jurídica. In: MOURA, Maria Aparecida (org.). A construção social do acesso público à informação no Brasil: contexto, historicidade e repercussões. Belo Horizonte: Editora UFMG, 2014.

MARTELETO, Regina Maria. Análise de redes sociais: aplicação nos estudos de transferência da informação. Revista Ciência da Informação, Brasília, v. 30, n. 1, p. 71-81, jan./abr. 2001.

MORAES, Marco Tulio Braga. Marco Civil da Internet no Brasil: das origens dos direitos fundamentais aos propósitos do direito de acesso à informação. Revista Democracia Digital e Governo Eletrônico, Florianópolis, v. 2, n. 9, p. 138-157, 2013.

MOREIRA, Poliana Bozégia. Direito ao Esquecimento. Revista de Direito, Viçosa, v. 7, n. 2, p. 293-317, 2015.

OLIVEIRA, Rafael Santos de; BARROS, Bruno Mello Corrêa de; GOULART, Gil Monteiro. As tecnologias da informação e comunicação na (des)construção das relações humanas contemporâneas: implicações de uso 
do Tinder. Revista Brasileira de Direito, Passo Fundo, v. 12, n. 1, p. 88-99, jan./jun, 2016.

PEREIRA, Adriano Cesar Machado et al. Tópicos em sistemas colaborativos, interativos, multimídia, web e banco de dados. Belo Horizonte: Sociedade Brasileira de Computação, 2010.

PEZZELLA, Maria Cristina Cereser; GHISI, Silvano. Privacidade na sociedade da informação: controle e direito ao esquecimento em espaços públicos. Revista da Associação dos Juízes do Rio Grande do Sul, Porto Alegre, v. 40, n. 132, p. 231-258, dez. 2013.

NASCIMENTO, Valéria Ribas do; RODRIGUES, Márcio Schorn. A sociedade informacional em xeque: princípio da publicidade versus direito à intimidade e a Lei 12.527/11. Revista de Direitos Fundamentais e Democracia, Curitiba, v. 14, n. 14, p. 181-195, jul./dez. 2013.

RODRIGUES, Georgete Medleg; OLIVEIRA, Eliane Braga. Memória e esquecimento no mundo virtual: os mesmos fios tecendo uma nova trama?

Revista do Laboratório Interdisciplinar sobre Informação e Conhecimento, Rio de Janeiro, v.11, n.1, p. 91-105, mai. 2015.

SANTOS, Cristiana Teixeira; ANDRADE, Francisco; NOVAIS, Paulo. Sinergia na resolução de litígios em linha e a necessidade de proteção da privacidade e dos dados pessoais. Revista Democracia Digital e Governo Eletrônico, Florianópolis, v. 1, n. 10, p. 341-359, 2014.

TEIXEIRA, Alumara Diniz; PAULA, Roberto de. Direito ao esquecimento em herança digital. Revista Judicare, Alta Floresta, v. 11, n. 1, p. 31-47, 2017.

UNIÃO EUROPEIA. Regulamento nº 2016/679, do Parlamento Europeu e do Conselho, de 27 de abril de 2016. Relativo à proteção das pessoas singulares no que diz respeito ao tratamento de dados pessoais e à livre circulação desses dados e que revoga a Diretiva 95/46/CE (Regulamento Geral sobre a Proteção de Dados). Jornal Oficial da União Europeia, Bruxelas, 27 abr. 2016.

VAZ, Ana Carolina. Neutralidade da rede, proteção de dados pessoais e Marco Regulatório da Internet no Brasil. Revista Democracia Digital e Governo Eletrônico, Florianópolis, v. 2, n. 5, p. 147-171, 2011. 


\title{
Heritage of digital information and the right to forget in social networks on line: a systematic literature review
}

\begin{abstract}
With the evolution and expansion of the Internet, we can observe the creation and diffusion of Online Social Networks, which are digital services to connect different users, through public or semi-public profiles. In this scenario, studies are beginning on social networks and their unfolding in society, such as digital inheritance, understood in a broad sense, such as the digital archive photos, messages, videos, etc. - left in life, by the user. After the inactivity of a user profile, due to his death, it is very important to give due treatment to this inheritance left by him. Therefore, the Right to Forgetfulness appears as a legal provision, which at its core proposes, on the one hand, the right to access information and freedom of expression and, on the other, the right to privacy and intimacy, capable of protecting the holder of determined data the faculty of seeing it erased, suppressed or blocked. Thus, the present article presents the result of a Systematic Review of Literature, with the purpose of verifying the current scenario of research on the Right to Forgetfulness and digital inheritance in the context of Online Social Networks and identifying under which focus the studies are being performed. It was possible to verify that in the current scenario of a society permeated by the resources offered by Information and Communication Technologies, most research focuses on the principles of intimacy and privacy, under the prerogative of the individual in face of this new society, which requires quick and legitimate answers for the preservation of his image and personality in the spaces where he passes.t
\end{abstract}

Keywords: Right to Forgetfulness. Digital Heritage. Social Networking Online. Digital legacy. Digital Information.

Recebido: 26/09/2018

Aceito:28/03/2019

${ }^{1}$ BEVILÁQUA, Clóvis. Direito das sucessões. Rio de Janeiro: Editora Rio, 1978. Apud Costa Filho (2016).

2 "O que é intransferível e inalienável, só podendo, pois, ser exercido pelo seu titular." (JUSBRASIL, c2019).

${ }^{3}$ Estimativa de usuários ativos da Internet em todo mundo.

${ }^{4}$ Classificação de qualidade definida pela Capes e realizada pelas áreas de avaliação e passa por processo anual de atualização. Esses veículos são enquadrados em estratos indicativos da qualidade - A1, o mais elevado; A2; B1; B2; B3; B4; B5; C - com peso zero.

5 BERNARDES, Marciele Berger. Democracia na sociedade informacional: o desenvolvimento da democracia digital nos municípios brasileiros. São Paulo: Saraiva, 2013, p.41.

6 AMARAL, Francisco. O direito civil na pós-modernidade. Revista Brasileira de Direito Comparado, Rio de Janeiro, n. 21, 2002. Apud Vaz (2011). 